\title{
An imperfect relationship between prospective memory and the prospective interference effect
}

\author{
M. Windy MCNeRney AND Robert West \\ University of Notre Dame, Notre Dame, Indiana
}

\begin{abstract}
Three experiments examined the functional relationship between the frequency of prospective responding and the prospective interference effect within the context of a task switching paradigm. Prospective responding was less frequent across the experiments when prospective cues appeared in switch blocks than when they appeared in pure blocks. The magnitude of the prospective interference effect for response time (RT) was similar for pure and switch blocks when exogenous task cuing was used, and was greater for switch blocks than for pure blocks when endogenous task cuing was used. These data reveal a dissociation between the effect of task switching on the frequency of prospective responding and the prospective interference effect, and indicate that the functional relationship between these two measures is dependent on task demands.
\end{abstract}

Prospective memory can be defined as the formation and realization of delayed intentions. An example of this would be if you were taking a shower and suddenly realized that you needed to return a video to the store. Instead of jumping out of the shower and rushing to the store, you would form the intention to return the video while shopping later in the day. The act of returning the video while shopping represents an instance of successful prospective memory. Considerable evidence indicates that the availability of working memory capacity or attentional resources is important for the realization of delayed intentions in some instances (Marsh \& Hicks, 1998; Smith, 2003; Smith \& Bayen, 2004). The present study was designed to further examine the functional relationship between the availability of working memory capacity and prospective memory in a task design wherein the availability of attentional resources was varied within the context of a task switching paradigm.

The preparatory attentional processes and memory processes (PAM) theory of prospective memory (Smith, 2003; Smith \& Bayen, 2004) represents one approach to characterizing the role of working memory capacity in relation to the realization of delayed intention. In this theory, the realization of delayed intentions is believed to be supported by both prospective and retrospective components (McDaniel \& Einstein, 1992). Preparatory processes support the detection or recognition of prospective cues, possibly through the activity of a monitoring process that serves to check the environment for potential cues such as the presence of the video store (Guynn, 2003; Smith, 2003). The engagement of preparatory processes draws working memory capacity away from the ongoing activity, resulting in a decrease in response accuracy and/or an increase in response time (RT) relative to when the ongoing activity is performed in isolation (Burgess, Quayle, \& Frith, 2001; Marsh, Hicks, Cook, Hansen, \& Pallos, 2003; Smith, 2003).

The change in performance for the ongoing activity from a control condition to a prospective memory condition has been labeled the prospective interference effect (Marsh et al., 2003). Within PAM theory, Smith and Bayen (2004) have proposed that there is a functional relationship between prospective memory and the magnitude of the prospective interference effect. Specifically, the engagement of capacity-consuming preparatory processes leads to a slowing of RT for ongoing activity trials with greater allocation of preparatory processes leading to an increase in the frequency of prospective hits (Smith \& Bayen, 2004). This leads to the prediction that as prospective memory performance decreases, resulting from a reduction in preparatory processing, the prospective interference effect for the ongoing task should also be attenuated.

Supporting the PAM theory, some research has revealed a positive correlation between the magnitude of the prospective interference effect and the accuracy of prospective memory, and the magnitude of the prospective interference effect and individual differences in working memory capacity (Smith, 2003). Other work utilizing a multinomial model instantiating the assumptions of PAM theory demonstrates that the $P$ parameter that reflects the probability of engaging preparatory processes is greater for individuals with high working memory capacity than for individuals with low working memory capacity (Smith \& Bayen, 2005). While available evidence is consistent with the idea that there is a functional relationship between the prospective interference effect and prospective memory, these data are largely correlational in nature. In view of this fact, one goal of the present study was to examine the nature of the relationship between prospective memory

M.W. McNerney, mmenerne@nd.edu 
and the prospective interference effect, using an experimental manipulation designed to vary the availability of working memory capacity in different task conditions.

An alternative explanation of the prospective interference effect is that it reflects the costs associated with a more general effect of divided attention or differences in attentional allocation (Marsh, Hicks, \& Cook, 2005; Marsh et al., 2003). This account is motivated by work examining the effects of divided attention on explicit episodic memory that has revealed the importance of considering the influence of divided attention on performance of both the primary and secondary tasks. For example, Craik, Govoni, Naveh-Benjamin, and Anderson (1996) found that dividing attention at encoding primarily affected memory performance (Baddeley, Lewis, Eldridge, \& Thomson, 1984); in contrast, dividing attention at retrieval had little effect on memory performance and led to an increase in RT for the secondary task. Furthermore, the effect of divided attention at retrieval on the secondary task increased as the retrieval demands of the primary task became greater (Craik et al., 1996). The latter finding leads to the prediction that an inverse relationship between the prospective interference effect and the frequency of prospective responding may become evident, as opposed to what is predicted on the basis of PAM theory. Given the findings of Craik and colleagues, it seems reasonable to expect that a decrease in prospective responding, resulting from an increase in the processing demands of the ongoing activity, could be associated with an increase in the magnitude of the prospective interference effect.

To vary the working memory, or attentional demands of the ongoing activity, we embedded a prospective memory task in a task switching paradigm, following Marsh, Hancock, and Hicks (2002). In three experiments, Marsh et al. (2002) found that there was a decrease in the frequency of prospective responding when prospective cues occurred in blocks of trials that required switching between two judgments, rather than when a single judgment was required for the ongoing activity. This effect was attributed to the increased demands placed on resources of the central executive component of working memory (Baddeley, 1986) when switching between tasks is required. This in turn resulted in capacity required for performance of the prospective aspect of the task (Marsh et al., 2002) being drawn away from processing.

Our study extends that of Marsh et al. (2002) in several ways. First, within the switch blocks half of the prospective cues were presented on alternation trials, where participants were required to switch between task sets, and half were presented on repetition trials, where participants performed the same task on consecutive trials. This allowed us to determine whether the effect of task switching on prospective memory was limited to trials on which a reconfiguration of task set was required. Second, we included prospective memory and control conditions to allow estimation of the prospective interference effect. This facilitated a consideration of the functional relationship between prospective responding and the prospective interference effect. On the basis of the prediction of PAM theory - that prospective accuracy would be positively associated with the prospective interference effect-we expected the accuracy of prospective memory and the prospective interference effect to be greater for pure blocks than for switch blocks. On the basis of the attentional allocation account, we expected the accuracy of prospective memory also to be greater for pure blocks than for switch blocks, while it is less clear what the effect of task switching would be on the prospective interference effect. A surprise recognition task for the prospective cues was administered following completion of the prospective memory task. This allowed us to examine both the effect of task switching on later explicit episodic memory for the prospective cues and the relationship between prospective memory and retrospective memory for the prospective cues. Given the disruptive effect of divided attention at encoding on retrospective memory, we predicted that recognition would be lower for prospective cues presented during switch blocks than during pure blocks.

\section{EXPERIMENT 1}

\section{Method}

Participants. Twenty individuals, recruited from the human subject pool of the Department of Psychology at the University of Notre Dame (mean age, 20.22 years; age range, 18-22 years), participated in the study, in exchange for course credit. Informed consent was obtained from participants prior to completion of the study.

Materials. Eight hundred words were chosen from a larger pool of 1,563 words reported in Balota, Cortese, and Pilotti (1999). These 800 words were divided into eight blocks of 100 trials with equal numbers of nouns and verbs, and words containing one or two vowels. Therefore, each block contained 50 nouns and 50 verbs and 50 words with one vowel and 50 words with two vowels. Across the eight blocks, the four word types were matched for familiarity based on the average ratings reported in Balota et al. There were 16 prospective cue words: rate, fight, jail, herb, goal, jaw, cite, gnaw, pluck, scarf, seed, boost, halt, sphere, streak, and church. Prospective cues were presented on Trials 25, 50, 75, and 100 for each block in the prospective condition. The prospective cues were selected so that there was an equal number of cues for each word type matched for the average familiarity ratings with the words presented in the ongoing activity trials.

Procedure. The experiment represented a 2 (prospective load: control, prospective memory) $\times 3$ (switch: pure, repetition, alternation) design that included two pure blocks and two switch blocks in each of the prospective load conditions. The order of presentation for the prospective memory and control conditions was counterbalanced across the participants, so that half received the prospective memory condition first and the control condition second. For the remaining participants, this order was reversed.

In the pure blocks, participants made the same type of judgment for the entire block; in the switch blocks, participants quasirandomly alternated between the two types of judgments. The switch blocks included equal numbers of repetition trials, in which the same judgment was made on consecutive trials, and alternation trials, in which different judgments were made from one trial to the next. The order of repetition and alternation trials was quasirandom, so that no trial type occurred more than seven times in succession.

Blocks were presented in the same ABBA order for all participants: a pure block first, followed by the two switch blocks, and then a second pure block. Each trial began with a cue, flashed on the computer monitor for $500 \mathrm{msec}$, indicating which judgment the participant should make for the upcoming word. After this, the screen was blank for $500 \mathrm{msec}$, then the word stimulus was presented and remained on the screen until a response was made. For the pure blocks, the same cue was presented for each trial; in the switch blocks, the 
cue alternated between the two types of judgments. The first pure block presented was associated with one type of judgment, whereas the second pure block was associated with the second type.

At the beginning of the task, participants were instructed to make one of two judgments, defined by the cue, for the words that were presented on the computer monitor. They could indicate either whether the word was a noun or a verb by pressing the " $\mathrm{n}$ " or " $\mathrm{m}$ " keys, respectively, or whether it had one or two vowels, again by using the " $n$ " and " $m$ " keys. The prospective memory aspect was modeled on Smith (2003). For this condition, participants encoded four words at the beginning of each block and were instructed to press the " $v$ " key whenever one of the words appeared, instead of making the judgment for the ongoing task. The four prospective cue words were presented on the screen at the beginning of each block and participants were allowed to study them for as long as they needed. Participants were instructed to respond as quickly and accurately as possible, and, after indicating that they completely understood the instructions, they were allowed to proceed with the task.

After completion of the task, participants were given an unexpected recognition test. They were handed a sheet containing 48 words that included the 16 prospective cue words, 16 words from the ongoing task, and 16 new words. Of the 16 ongoing activity words, 8 were from the pure blocks and 8 were from the switch blocks. Participants were asked to circle the prospective cue words and were not informed how many words they should circle. Participants were given as long as they needed to complete the recognition test. The experimental session lasted approximately $40 \mathrm{~min}$.

\section{Results and Discussion}

All statistical effects were significant at the $p<.05$ level, unless otherwise noted.

The frequency of correct prospective responses was higher for the pure blocks $(M=.47, S D=.36)$ than for the switch blocks $(M=.29, S D=.25)[t(19)=3.278$, $S E=.47]$. The $18 \%$ decrease in accuracy from the pure to the switch blocks generally replicates that reported by Marsh et al. (2002). The effect of task switching on prospective memory was similar for repetition trials $(M=$ $.31, S D=.32)$ and alternation trials $(M=.24, S D=.27)$ $[t(19)=1.00, p>.33]$. In addition, prospective accuracy for pure trials differed from repetition trials $[t(19)=$ 3.633, $S E=.037]$ and from alternation trials $[t(19)=$ $2.123, S E=.041]$. This finding indicates that the effect of task switching on prospective memory did not result from the specific requirement to switch between task sets on alternation trials, but instead arose from a more general effect of the requirement to manage multiple task sets.

The percent correct data and mean RT for correct responses for the ongoing activity trials are presented in Tables 1 and 2 . These data were analyzed into a set of 2 (prospective load: control, prospective memory) $\times 3$ (switch: pure, repetition, alternation) ANOVAs. In the analysis of the accuracy data, none of the effects were significant [prospective load, $F<1.00$; switch, $F(2,38)=1.01$, $M S_{\mathrm{e}}=118.28, p>.329$; prospective load $\times$ switch, $F<$ $1.00]$. For the RT data, there was a significant main effect of the prospective load $\left[F(1,19)=43.302, M S_{\mathrm{e}}=45,754\right.$, $\left.\eta^{2}=.695\right]$, revealing a robust prospective interference effect. A significant main effect of switch $[F(2,38)=63.99$, $\left.M S_{\mathrm{e}}=27,868, \eta^{2}=.769\right]$, indicating that RT increased from pure trials to repetition trials to alternation trials. The prospective load $\times$ switch interaction was not significant $(F<1)$, indicating that the prospective interference effect
Table 1

Proportion Correct for the Ongoing Task by Prospective Load Condition

\begin{tabular}{|c|c|c|c|c|}
\hline & \multicolumn{2}{|c|}{ Control Task } & \multicolumn{2}{|c|}{$\begin{array}{c}\text { Prospective } \\
\text { Memory Task }\end{array}$} \\
\hline & $M$ & $S D$ & $M$ & $S D$ \\
\hline \multicolumn{5}{|c|}{ Experiment 1} \\
\hline Pure & .91 & .06 & .83 & .05 \\
\hline Repetition & .92 & .10 & .88 & .05 \\
\hline Alternation & .90 & .10 & .87 & .07 \\
\hline \multicolumn{5}{|c|}{ Experiment 2} \\
\hline Pure & .85 & .06 & .91 & .02 \\
\hline Repetition & .91 & .05 & .91 & .05 \\
\hline Alternation & .92 & .06 & .91 & .06 \\
\hline \multicolumn{5}{|c|}{ Experiment 3} \\
\hline Pure & .98 & .05 & .99 & .07 \\
\hline Repetition & - & - & - & - \\
\hline Alternation & .92 & .17 & .98 & .02 \\
\hline
\end{tabular}

was insensitive to the requirement to switch between task sets. This finding, together with the significant effect of task switching on the accuracy of prospective memory, fails to reveal the functional relationship between the prospective interference effect and prospective responding that was expected, on the basis of PAM theory.

The hit and false alarm rates for the recognition test are presented in Table 3 . Hits were more frequent than false alarms for new items $[t(19)=9.418, S E=.046]$ or for ongoing activity stimuli $[t(19)=5.85, S E=.059]$; and false alarms for ongoing activity items and new items differed $[t(19)=-3.63, S E=.02]$. These results indicate that participants were able to discriminate between the prospective cues and words that were presented in the ongoing task. To examine the effect of task switching on recognition, we performed a $t$ test on corrected recogni-

Table 2

Response Times (in Milliseconds) for the Ongoing Task by Prospective Load Condition

\begin{tabular}{|c|c|c|c|c|c|}
\hline \multicolumn{6}{|c|}{ Prospective Load Condition } \\
\hline & \multirow{2}{*}{\multicolumn{2}{|c|}{ Control Task }} & \multirow{2}{*}{\multicolumn{2}{|c|}{$\begin{array}{c}\text { Prospective } \\
\text { Memory Task } \\
\end{array}$}} & \multirow{3}{*}{$\begin{array}{l}\text { Prospective } \\
\text { Interference }\end{array}$} \\
\hline & & & & & \\
\hline & $M$ & $S D$ & $M$ & $S D$ & \\
\hline \multicolumn{6}{|c|}{ Experiment 1} \\
\hline Pure & 910 & 117 & 1,165 & 291 & 255 \\
\hline Repetition & 1,160 & 292 & 1,421 & 358 & 261 \\
\hline Alternation & 1,279 & 361 & 1,534 & 452 & 255 \\
\hline Mixing cost & 250 & - & 256 & - & - \\
\hline Switch cost & 119 & - & 113 & - & - \\
\hline \multicolumn{6}{|c|}{ Experiment 2} \\
\hline Pure & 975 & 216 & 1,151 & 294 & 176 \\
\hline Repetition & 1,253 & 281 & 1,475 & 385 & 222 \\
\hline Alternation & 1,408 & 395 & 1,628 & 430 & 220 \\
\hline Mixing cost & 278 & - & 324 & - & - \\
\hline Switch cost & 155 & - & 153 & - & - \\
\hline \multicolumn{6}{|c|}{ Experiment 3} \\
\hline Pure & 1,052 & 153 & 1,263 & 271 & 211 \\
\hline Repetition & - & - & - & - & - \\
\hline Alternation & 1,589 & 288 & 1,945 & 397 & 356 \\
\hline Mixing cost & - & - & - & - & - \\
\hline Switch cost & 537 & - & 682 & - & - \\
\hline
\end{tabular}


Table 3

Hit and False Alarm (FA) Rates for Prospective Memory (PM) Cues by Switch Condition

\begin{tabular}{|c|c|c|c|c|c|c|}
\hline & \multicolumn{2}{|c|}{ Pure } & \multicolumn{2}{|c|}{ Switch } & \multicolumn{2}{|c|}{ Total } \\
\hline & $M$ & $S D$ & $M$ & $S D$ & $M$ & $S D$ \\
\hline \multicolumn{7}{|c|}{ Experiment 1} \\
\hline PM cue hits & .60 & .20 & .34 & .24 & .47 & .18 \\
\hline Old FA & .09 & .13 & .13 & .16 & .11 & .14 \\
\hline New FA & - & - & - & - & .03 & .06 \\
\hline \multicolumn{7}{|c|}{ Experiment 2} \\
\hline PM cue hits & .56 & .19 & .45 & .21 & .51 & .17 \\
\hline Old FA & - & - & - & - & - & - \\
\hline New FA & - & - & - & - & .04 & .06 \\
\hline \multicolumn{7}{|c|}{ Experiment 3} \\
\hline PM cue hits & .52 & .25 & .43 & .30 & .48 & .25 \\
\hline Old FA & - & - & - & - & - & - \\
\hline New FA & - & - & - & - & .15 & .15 \\
\hline
\end{tabular}

tion (hits - ongoing activity false alarms) for the pure and switch blocks. Corrected recognition was higher for pure blocks $(M=.51)$ than for switch blocks $(M=.31)$ $[t(19)=4.57, S E=.07]$. These results are consistent with the hypothesis that task switching would have a similar effect on the later recognition of prospective cues as divided attention at encoding has on later memory for items in conventional explicit episodic memory paradigms. The correlation between recognition hits for prospective cues and prospective responding was significant $[r(18)=.48]$. This finding is consistent with the idea that similar processes may contribute to prospective memory and explicit episodic memory (Einstein \& McDaniel, 1996; Guynn, McDaniel, \& Einstein, 2001).

One limitation of the finding that task switching disrupted recognition for the prospective cues is that this effect cannot be unambiguously interpreted merely on the basis of the corrected recognition data, given differences in the rate of prospective responding in the pure and switch blocks. If one assumes that a prospective response serves as a form of elaborative processing of the cues, the effect of task switching on recognition might also be interpreted as reflecting differences in the nature of processing, rather than simply the degree of processing. To examine this issue, we classified prospective cues into one of four categories that allowed us to control for differences in prospective responding: prospective hit-recognition hit; prospective hit-recognition miss; prospective missrecognition hit; prospective miss-recognition miss. These data are presented in Table 4. The number of prospective hit-recognition hit trials was greater in the pure blocks than in the switch blocks $[t(19)=4.004, S E=.39]$, and the number of prospective miss-recognition miss trials was greater in the switch blocks than in the pure blocks $[t(19)=-4.06, S E=.51]$. Together, these findings reveal an effect of task switching on the frequency of recognition hits and misses when the level of processing attributable to prospective responding is held constant, providing further evidence that task switching has an effect similar to divided attention at encoding on later explicit episodic memory for the prospective cues.

\section{EXPERIMENT 2}

Experiment 1 failed to reveal a functional relationship between prospective responding and the prospective interference effect. One possible explanation of this finding is that prospective accuracy for the pure and switch blocks was rather low (.47 and .28 , respectively) relative to that reported in previous studies (Marsh et al., 2002; Marsh et al., 2003; Smith, 2003). This low level of prospective responding may have resulted from a failure to adequately encode the prospective cues, since no particular strategy was given to individuals to foster the formation of an association between the cues and the prospective response. In an effort to elevate levels of prospective memory into a range more comparable to that reported in past research, the prospective cues in Experiment 2 were defined by semantic category membership (i.e., animals). ${ }^{1}$ This type of prospective cue has been used extensively by Marsh and colleagues (Marsh et al., 2002; Marsh et al., 2003), and tends to result in higher levels of prospective responding than were observed in Experiment 1.

\section{Method}

Participants. Thirty-two individuals (mean age, 19.78 years; age range, 18-23 years) were recruited from the University of Notre Dame and participated in exchange for course credit. Data for 2 participants were not included in the analyses due to their poor performance on the ongoing activity trials $(3+S D$ s below the group mean). Informed consent was obtained from participants prior to completion of the study.

Materials and Design. The materials and design for the ongoing activity were identical to those in Experiment 1 . For the prospective memory aspect of the task, participants were given a semantic category for the prospective cue. They were instructed to make a prospective response by pressing the "v" key whenever an animal word-pig, wolf, frog, cow, bull, pup, bear, sheep, snake, trout, roach, fox, rat, ape, crab, bee - appeared in the task. Four animal words were presented in each block of the prospective condition at Trials $25,50,75$, and 100 . The animal words were matched for familiarity with the block average.

Table 4

Recognition Data Conditionalized on the Success of Prospective Memory

\begin{tabular}{|c|c|c|c|c|}
\hline \multirow{2}{*}{$\begin{array}{l}\text { Hits and } \\
\text { Misses }\end{array}$} & \multicolumn{2}{|c|}{ Pure } & \multicolumn{2}{|c|}{ Switch } \\
\hline & $M$ & $S D$ & $M$ & $S D$ \\
\hline \multicolumn{5}{|c|}{ Experiment 1} \\
\hline $\mathrm{PM}+\mathrm{RM}+$ & 2.85 & 2.26 & 1.30 & 1.26 \\
\hline $\mathrm{PM}+\mathrm{RM}-$ & 0.90 & 1.02 & 0.90 & 0.117 \\
\hline $\mathrm{PM}-\mathrm{RM}+$ & 1.85 & 1.51 & 1.35 & 1.35 \\
\hline $\mathrm{PM}-\mathrm{RM}-$ & 2.40 & 2.01 & 4.45 & 2.16 \\
\hline \multicolumn{5}{|c|}{ Experiment 2} \\
\hline $\mathrm{PM}+\mathrm{RM}+$ & 3.60 & 1.69 & 2.37 & 1.54 \\
\hline $\mathrm{PM}+\mathrm{RM}-$ & 1.80 & 1.30 & 2.07 & 1.57 \\
\hline $\mathrm{PM}-\mathrm{RM}+$ & 0.90 & 0.93 & 1.20 & 1.03 \\
\hline $\mathrm{PM}-\mathrm{RM}-$ & 1.70 & 1.66 & 2.37 & 1.52 \\
\hline \multicolumn{5}{|c|}{ Experiment 3} \\
\hline $\mathrm{PM}+\mathrm{RM}+$ & 3.19 & 1.67 & 1.65 & 1.79 \\
\hline $\mathrm{PM}+\mathrm{RM}-$ & 2.35 & 1.44 & 2.50 & 1.93 \\
\hline $\mathrm{PM}-\mathrm{RM}+$ & 1.19 & 1.27 & 1.62 & 1.70 \\
\hline $\mathrm{PM}-\mathrm{RM}-$ & 1.35 & 1.60 & 2.23 & 1.99 \\
\hline
\end{tabular}

Note- $\mathrm{PM}+$, prospective hit; $\mathrm{RM}+$, recognition hit; $\mathrm{PM}-$, prospective miss; $\mathrm{RM}-$, recognition miss. 
A surprise recognition test was given to participants following completion of the prospective memory task. This consisted of a list of 32 animal words, 16 of which were the prospective cue words and 16 of which were new words not presented in the task. Participants were asked to circle the words that were prospective cues.

\section{Results and Discussion}

The proportion of correct prospective responses was higher for pure blocks $(M=0.70, S D=.29)$ than for the switch blocks $(M=0.57, S D=.26)[t(29)=2.89, S E=$ .046], and was comparable to that reported by Marsh et al. (2002). As was the case in Experiment 1, prospective accuracy was not significantly different for repetition trials $(M=.63, S D=.27)$ and alternation trials $(M=.52$, $S D=.33)[t(29)=1.90, S E=.23, p>.05]$.

The percent correct data and mean RTs for correct ongoing activity trials are presented in Tables 1 and 2 . These data were analyzed in a set of 2 (prospective load: control, prospective memory) $\times 3$ (switch: pure, repetition, alternation) ANOVAs. Analysis of the response accuracy data for the ongoing activity revealed main effects of prospective load $\left[F(1,29)=9.66, M S_{\mathrm{e}}=0.002, \eta^{2}=.250\right]$ and of switch $\left[F(2,58)=14.13, M S_{\mathrm{e}}=0.002, \eta^{2}=.328\right]$, and a significant interaction $\left[F(2,58)=15.90, M S_{\mathrm{e}}=0.001\right.$, $\left.\eta^{2}=.354\right]$. The interaction resulted from low accuracy for pure blocks in the control condition relative to the prospective load condition ${ }^{2}$; in contrast, response accuracy in the switch blocks was not sensitive to prospective load. The analysis of the RT data revealed a main effect of prospective load $\left[F(1,29)=17.092, M S_{\mathrm{e}}=114,487, \eta^{2}=.371\right]$ and a main effect of switch $\left[F(2,28)=63.582, M S_{\mathrm{e}}=45,597\right.$, $\left.\eta^{2}=.776\right]$. The interaction was not significant $(F<1.00)$.

The recognition data revealed a significant difference between recognition hits for prospective cues $(M=.51$, $S D=.17)$ and false alarms for new animal words $(M=$ $.04, S D=.06)[t(29)=15.703, S E=.029]$, demonstrating that participants were able to discriminate between prospective cue words and new words. Recognition hits for prospective cues were more frequent for pure blocks $(M=.56, S D=.19)$ than for switch blocks $(M=.45$, $S D=.21)[t(29)=2.728, S E=.04]$, consistent with the idea that the requirement to switch between tasks should disrupt encoding of the prospective cues. As in Experiment 1 , the data were conditionalized on the probability of prospective responding. Prospective hit-recognition hit trials were more frequent in the pure blocks than in the switch blocks $[t(29)=3.275, S E=.377]$, and prospective miss-recognition miss trials were more frequent in the switch blocks than in the pure blocks $[t(29)=-2.04$, $S E=.32]$ (Table 4). These data again demonstrate the effect of task switching on later recognition after controlling for differences in processing attributable to prospective responding. The correlation between recognition hits for prospective cues and prospective responding was again significant $[r(28)=.507]$.

\section{EXPERIMENT 3}

In Experiment 2, we were able to elevate levels of prospective memory; this did not, however, result in a significant interaction between prospective load and the requirement to switch between task sets. These findings remain inconsistent with predictions derived from PAM theory. One potential limitation of this finding is that some investigators have argued that exogenous cuing in task switching may not necessarily require the engagement of an endogenous act of control, and may therefore place few demands on working memory capacity (Logan \& Bundesen, 2003). Given this fact, in Experiment 3 we utilized a task that required endogenous cuing wherein participants had to keep track of which task set was relevant for a given trial in the absence of external cues. This was accomplished by removing the cues indicating which of the two judgments should be performed for the ongoing task and requiring participants to switch between tasks after each trial. The use of endogenous cuing should ensure that the switch condition requires the allocations of working memory capacity in order to update which of the two task sets is required for a given trial.

\section{Method}

Participants. Twenty-six individuals were recruited from the University of Notre Dame (mean age, 19.39 years; age range, 1722 years) and participated in exchange for course credit. Informed consent was obtained from participants prior to completion of the study.

Materials and Design. The materials for the prospective memory aspect of the task were identical to Experiment 2. The ongoing activity was also the same, except that cues indicating which of the judgments to make were not presented. For the pure blocks, the participants were instructed to make the same judgment for all trials, and to alternate between noun and verb or 1 to 2 vowel judgments for the switch blocks. The " $n$ " and " $m$ " keys were again used to indicate noun and verb judgments, and the " $z$ " and " $x$ " keys were used for the one or two vowel judgments, respectively. The change in key mapping was necessary to ensure that the participants were alternating between judgments in the switch blocks. For the first switch block, participants started with a vowel judgment and to alternate from there, in the second switch block, participants started with a noun/verb judgment. The switch blocks were not separated into repetitions and alternations, as every trial required an alternation. A recognition test identical to that used in Experiment 2 was administered following completion of the prospective task.

\section{Results and Discussion}

The proportion of correct prospective responses was higher for the pure blocks $(M=0.68, S D=.27)$ than for the switch blocks $(M=0.50, S D=.28)[t(25)=3.20$, $S E=.059, p<.004]$, and closely matched that reported in Experiment 2.

The percent correct data and mean RT for correct ongoing trials are presented in Tables 1 and 2. These data were analyzed in a set of 2 (prospective load: control, prospective memory) $\times 2$ (switch: pure, switch) ANOVAs. Analysis of the response accuracy data did not reveal any significant effects, prospective load $[F(1,25)=3.185$, $\left.M S_{\mathrm{e}}=0.01, p>.086, \eta^{2}=.113\right]$, switch $[F(1,25)=$ $\left.2.626, M S_{\mathrm{e}}=0.01, p>.118, \eta^{2}=.126\right]$, and prospective load $\times$ switch $\left[F(1,25)=3.601, M S_{\mathrm{e}}=0.009, p>.069\right.$, $\left.\eta^{2}=.095\right]$. Analysis of the RT data revealed main effects of prospective load $\left[F(1,25)=30.89, M S_{\mathrm{e}}=63,646, \eta^{2}=\right.$ $.553]$ and of switch $\left[F(1,25)=220.08, M S_{\mathrm{e}}=45,086\right.$, $\left.\eta^{2}=.898\right]$, and an interaction between prospective load 
and switch $\left[F(1,25)=5.48, M S_{\mathrm{e}}=19,093, \eta^{2}=.180\right]$. The significant interaction reveals that the prospective interference effect was greater for the switch blocks than for the pure blocks and lends support to the attentional allocation account of the prospective interference effect.

The recognition data revealed a significant difference between recognition hits for prospective cues $(M=.48$, $S D=.25)$ and false alarms $(M=.15, S D=.15)[t(25)=$ $8.036, S E=.04]$, demonstrating that participants were able to discriminate between prospective cues and new animal words. The recognition hit rate for prospective cues was higher for the pure blocks $(M=.52, S D=.25)$ than for the switch blocks $(M=.43, S D=.30)$, although this difference was only marginally significant $[t(25)=$ $2.00, S E=.05, p=.057]$. Additionally, the frequency of prospective hit-recognition hit trials was greater for pure blocks than for switch blocks $[t(25)=4.170, S E=.369]$, as was the frequency of prospective miss-recognition miss trials $[t(25)=-2.184, S E=.405]$ (Table 4). The correlation between recognition hits for prospective cues and prospective responses was not significant $[r(24)=$ $-.034, p=.869$ ], differing from the pattern that was observed in the first two experiments.

\section{GENERAL DISCUSSION}

The present study was designed to examine two accounts of the prospective interference effect in a task in which we could experimentally vary the processing demands of the ongoing activity. On the basis of the PAM theory (Smith, 2003), we predicted that increasing the attentional demands of the ongoing activity would lead to a decrease in the rate of prospective responding, as well as to a decrease in the magnitude of the prospective interference effect. In contrast, on the basis of the attentional allocation account, we predicted that the magnitude of the prospective interference effect might increase with the attentional demands of the ongoing activity. In three experiments, the attentional demands of the ongoing activity were varied within the context of a task switching paradigm with the idea that switch blocks would demand greater attentional resources than would pure blocks (Rogers \& Monsell, 1995). Supporting this proposal, recognition of prospective cues following completion of the prospective memory task was lower for prospective cues that occurred in switch blocks than for those that occurred in pure blocks, and this effect could not be attributed to differences in prospective responding. This finding is similar to extensive evidence from the explicit episodic memory literature demonstrating that divided attention at encoding disrupts explicit episodic memory for stimuli when tested using a variety of methods (Craik et al., 1996; Fernandes \& Moscovitch, 2000; Naveh-Benjamin, Craik, Guez, \& Dori, 1998).

Across the three experiments, the rate of prospective responding was lower when prospective cues were presented in switch blocks than when they were presented in pure blocks. The magnitude of the task switching effect on prospective memory was roughly $15 \%$ across the experiments. This effect is similar to that reported by Marsh et al.
(2002) in a paradigm utilizing different ongoing activity and prospective memory aspects of the task. The present findings extend those of Marsh et al. (2002) in two ways. First, our data demonstrate that the effect of switching on prospective memory was similar for repetition and alternation trials. This finding indicates that the costs of task switching on prospective memory was not specifically tied to the requirement to reconfigure task set, but was instead associated with a more general process that may be related to the requirement to manage competing task goals (Gilbert, Frith, \& Burgess, 2005). Second, our data demonstrate that similar effects of task switching are observed when either exogenous task cuing (Experiments 1-2) or endogenous task cuing (Experiment 3 ) were used, again revealing a rather general effect of task switching on prospective memory that was not heavily dependent on the unique demands of the ongoing activity.

If the effect of task switching on prospective memory is not specifically tied to the costs of switching between tasks, one may wonder where the locus of this effect resides. One possibility is that the effect is observed when multiple task sets, or goals, compete for access to and control over the information processing system. This proposal is derived from recent work examining the functional neuroanatomy of prospective memory and task switching. Evidence from a number of studies has revealed sustained activation in lateral rostral prefrontal cortex (PFC) that is greater during task conditions requiring prospective memory than for task conditions in which only the ongoing activity is performed (Burgess et al., 2001; Reynolds, West, \& Braver, 2003). Other work has demonstrated a similar pattern of recruitment in this region in switch blocks relative to pure blocks (Braver, Reynolds, \& Donaldson, 2003). Importantly, there is some evidence that recruitment of lateral rostral PFC in the service of prospective memory is sensitive to the attentional or working memory demands of the ongoing activity (Reynolds et al., 2003). In this study, lateral rostral PFC was more strongly activated when the prospective aspect of the task was embedded in a 1-back working memory task than when it was embedded in a 3-back working memory task. These findings lead to the suggestion that the effect of task switching on prospective memory results from an intersection of the processing demands of the two components of the task when competing goals are represented in the task set. This interpretation of the effect of task switching on prospective memory is consistent with evidence from the literature related to the effects of divided attention on explicit episodic memory when the task demands attentional resources (Hicks \& Marsh, 2000). In these studies, the greatest effect of divided attention is observed when primary and secondary tasks compete for a common processing resource (Fernandes \& Moscovitch, 2000).

The effect of task switching on the prospective interference effect for the RT data was dependent on the nature of the task switching paradigm. In all experiments, a robust prospective interference effect was observed. In Experiments 1 and 2, where exogenous cuing of task set was used, the prospective interference effect was not sensitive to task switching. In contrast, in Experiment 3, where 
endogenous cuing was used, the prospective interference effect was greater for switch blocks than for pure blocks. The finding that the prospective interference effect was sensitive to task switching with endogenous but not exogenous cuing is consistent with previous research demonstrating that prospective memory is particularly dependent on the availability of central executive resources (Marsh \& Hicks, 1998) that would presumably be required to keep track of which task set was relevant with endogenous task cuing. Differences in the effect of task switching on the prospective interference effect across the experiments also seem consistent with the idea that this effect is at least partially determined by the attentional allocation policy for the entire task set adopted by participants over the course of task performance (Marsh et al., 2005) and therefore may not be functionally related to the accuracy of prospective memory. Given that RT was roughly 180 to $300 \mathrm{msec}$ slower for switch trials in Experiment 3 than in Experiment 2, it seems reasonable to expect that individuals would have found the task in Experiment 3 more difficult than in Experiment 2, leading to variation in attentional allocation between the two components of the task across the experiments.

The findings of Experiments 1-3 reveal a dissociation between the effect of task switching on the accuracy of prospective responding and the prospective interference effect that is inconsistent with predictions derived from the PAM theory. Specifically, in Experiments 1 and 2 there appeared to be no functional relationship between prospective responding and the prospective interference effect, since prospective responding - but not the prospective interference effect-was sensitive to task switching. Furthermore, when a functional relationship was observed between prospective responding and the prospective interference effect in Experiment 3, it was in the opposite direction of what would be expected on the basis of the PAM theory, and was consistent with predictions derived from the attentional allocation account of the prospective interference effect. Together, these findings indicate that the relationship between prospective memory and the allocation of working memory capacity may not be as straightforward as is portrayed in PAM theory, leading to the suggestion that further conceptual and empirical work is necessary in order to fully appreciate the relationship between working memory capacity and prospective memory.

In summary, data from our three experiments reveal robust effects of task switching on the efficiency of prospective memory. Across all experiments, the frequency of prospective hits and the likelihood of later recognition of prospective cues were lower when prospective cues were presented in switch blocks than when they were presented in pure blocks. The prospective interference effect was greater for switch blocks than for pure blocks when endogenous cuing was used and was insensitive to exogenous cuing. The dissociation between the effect of task switching on prospective responding and the prospective interference effect fails to reveal the functional relationship that is posited between these two measures in PAM theory, and may support the attentional allocation ac- count of the prospective interference effect (Marsh et al., 2003).

\section{AUTHOR NOTE}

R.W. is now at the Department of Psychology, Iowa State University. Correspondence concerning this article should be sent to M. W. McNerney, 118 Haggar Hall, University of Notre Dame, Notre Dame, IN 46556 (e-mail: mmcnerne@nd.edu).

\section{REFERENCES}

BAdDELey, A. [D.] (1986). Working memory. New York: Oxford University Press.

Baddeley, A. D., Lewis, V., Eldridge, M., \& Thomson, N. (1984). Attention and retrieval from long-term memory. Journal of Experimental Psychology: General, 113, 518-540.

Balota, D. A., Cortese, M. J., \& Pilotti, M. (1999, November). Itemlevel analysis of lexical decision performance: Results from a megastudy. Poster presented at the 40th Annual Meeting of the Psychonomic Society, Los Angeles.

Braver, T. S., Reynolds, J. R., \& Donaldson, D. I. (2003). Neural mechanisms of transient and sustained cognitive control during task switching. Neuron, 39, 713-726.

Burgess, P. W., QuaYle, A., \& Frith, C. D. (2001). Brain regions involved in prospective memory as determined by positron emission tomography. Neuropsychologia, 39, 545-555.

Craik, F. I. M., Govoni, R., Naveh-Benjamin, M., \& Anderson, N. D. (1996). The effects of divided attention on encoding and retrieval processes in human memory. Journal of Experimental Psychology: General, 125, 159-180.

Einstein, G. O., \& McDaniel, M. A. (1996). Retrieval processes in prospective memory: Theoretical approaches and some new empirical findings. In M. Brandimonte, G. O. Einstein, \& M. A. McDaniel (Eds.), Prospective memory: Theory and applications (pp. 115-141). Mahwah, NJ: Erlbaum.

Fernandes, M. A., \& Moscovitch, M. (2000). Divided attention and memory: Evidence of substantial interference effects at retrieval and encoding. Journal of Experimental Psychology: General, 129, $155-176$.

Gilbert, S., Frith, C. D., \& Burgess, P. W. (2005). Involvement of rostral prefrontal cortex in selection between stimulus-oriented and stimulus-independent thought. European Journal of Neuroscience, 21, 1423-1431.

GuYNN, M. J. (2003). A two-process model of strategic monitoring in event-based prospective memory: Activation/retrieval mode and checking. International Journal of Psychology, 38, 245-256.

Guynn, M. J., McDaniel, M. A., \& Einstein, G. O. (2001). Remembering to perform actions: A different type of memory? In H. D. Zimmer, R. L. Cohen, M. J. Guynn, J. Engelkamp, R. Kormi-Nouri, \& M. A. Foley (Eds.), Memory for action: A distant form of episodic memory? (pp. 25-48). Oxford: Oxford University Press.

Hicks, J. L., \& MARSH, R. L. (2000). Toward specifying the attentional demands of recognition memory. Journal of Experimental Psychology: Learning, Memory, \& Cognition, 26, 1483-1498.

LogAn, G. D., \& Bundesen, C. (2003). Clever homunculus: Is there an endogenous act of control in the explicit task-cuing procedure? Journal of Experimental Psychology: Human Perception \& Performance, 29, 575-599.

Marsh, R. L., Hancock, T. W., \& Hicks, J. L. (2002). The demands of an ongoing activity influence the success of event-based prospective memory. Psychonomic Bulletin \& Review, 9, 604-610.

Marsh, R. L., \& Hicks, J. L. (1998). Event-based prospective memory and executive control of working memory. Journal of Experimental Psychology: Learning, Memory, \& Cognition, 24, 336-349.

MARSH, R. L., HICKS, J. L., \& CoOK, G. I. (2005). On the relationship between effort toward an ongoing task and cue detection in event-based prospective memory. Journal of Experimental Psychology: Learning, Memory, \& Cognition, 31, 68-75.

Marsh, R. L., Hicks, J. L., Cook, G. I., Hansen, J. S, \& Pallos, A. L. (2003). Interference to ongoing activities covaries with the characteristics of an event-based intention. Journal of Experimental Psychology: Learning, Memory, \& Cognition, 29, 861-870. 
McDaniel, M. A., \& Einstein, G. O. (1992). Aging and prospective memory: Basic findings and practical applications. Advances in Learning \& Behavioral Disabilities, 7, 87-103.

McDaniel, M. A., \& Einstein, G. O. (2000). Strategic and automatic processes in prospective memory retrieval: A multiprocess framework. Applied Cognitive Psychology, 14, S127-S144.

Naveh-Benjamin, M., Craik, F. I. M., Guez, J., \& Dori, H. (1998). Effects of divided attention on encoding and retrieval processes in human memory: Further support for an asymmetry. Journal of Experimental Psychology: Learning, Memory, \& Cognition, 24, 1091-1104.

Reynolds, J., West, R., \& Braver, T. (2003). Differentiation of prospective memory and working memory using a mixed state and eventrelated fMRI design [Abstract]. Journal of Cognitive Neuroscience: Supplement, p. 147.

Rogers, R. D., \& Monsell, S. (1995). Cost of a predictable switch between simple cognitive tasks. Journal of Experimental Psychology: General, 124, 207-231.

Smith, R. E. (2003). The cost of remembering to remember in eventbased prospective memory: Investigating the capacity demands of delayed intention performance. Journal of Experimental Psychology: Learning, Memory, \& Cognition, 29, 347-361.

SMith, R. E., \& BAYEN, U. J. (2004). A multinomial model of event- based prospective memory. Journal of Experimental Psychology: Learning, Memory, \& Cognition, 30, 756-777.

SMIth, R. E., \& BAYEN, U. J. (2005). The effects of working memory resource availability on prospective memory: A formal modeling approach. Experimental Psychology, 52, 243-256.

\section{NOTES}

1. The use of categorical cues relative to explicit cues to elevate prospective memory may seem counterintuitive given that the latter tends to produce higher levels of prospective memory (McDaniel \& Einstein, 2000). However, it seems that for our particular paradigm the encoding demands associated with the categorical cue (look for animal words across the task) are probably diminished relative to the demands of encoding 16 unique words distributed over four blocks of trials.

2. The low accuracy in the pure condition of Experiment 2 did not appear to arise from the inclusion of outliers in the data set and was not observed in Experiments 1 or 3. Given this, we suspect that the effect reflects a local aberration that is not generally reflective of task performance.

(Manuscript received September 20, 2005; revision accepted for publication January 31, 2006.) 